\title{
EXPERIMENTAL INVESTIGATION OF CONICAL PERIPHERAL JET NORMALLY IMPINGING ON A FLAT PLATE *
}

\author{
Ibrahim A. M. Gad ${ }^{+}$ \\ Faculty of Engineering, Zagazig University, Egypt.
}

\begin{abstract}
:
A new configuration peripheral air jet model of annular-conical convergent nozzle positioned in proximity with a flat plate to create air cushioned in between with high pressure is investigated experimentally. Different model configurations obtained by varying some jet parameters like as; annular thickness $t_{j}$, conic angle $\theta_{j}$, nozzle-plate spacing $L_{j}$ and jet velocity $V_{j}$ are tested. The time average pressure distributions at the created air cushion and its surroundings; impinged plate, platform, nozzle exit and plenum chamber are measured. A power-height parameter $C_{h d}$ which serves as a good measure for the relative power requirements of selected nozzle configurations is calculated by the exponential potential theory and estimated from the present measurements. The experimental results of $C_{h d}$ has the same trend as its predicted values with reasonable differences. In all configurations the ratio of nozzle-plate spacing to upper platform diameter $L_{j} / D_{c}$ has strong effects on cushion characteristics and $L_{j} / D_{c}=0.1$ may be considered as a critical value over which the cushion begins to explode producing irregularly with time.
\end{abstract}

KEYWORDS: peripheral jet, conical jet, annular jet, air cushion

\section{ÉTUDE EXPERIMENTALE DE JET PERIPHERIQUE CONIQUE NORMALEMENT EMPIETER SUR UNE PLAQUE PLANE}

\section{RÉSUMÉ:}

Une nouvelle configuration périphérique modèle à jet d'air de la buse convergente annulaire conique placé à proximité d'une plaque plane de créer sur coussin d'air entre la haute pression est étudiée expérimentalement. Différentes configurations du modèle obtenu en faisant varier certains paramètres comme le jet que; annulaire】 épaisseur $t_{j}$, angle conique $\theta_{j}$, buse-plaque espacement $L_{j}$ et jet vitesse $V_{j}$ sont testés. Les distributions de temps de la pression moyenne à coussin d'air créé et ses environs; plaque empiété, plate-forme, sortie de la tuyère et la chambre de tranquillisation est mesurée. Un paramètre de puissance-hauteur $C_{h d}$ qui sert une bonne mesure pour les exigences de puissance relative des configurations de buse choisie est calculé par la théorie exponentielle potentielle et estimée à partir des mesures actuelles. Les résultats expérimentaux de $C_{h d}$ a la même tendance que ses valeurs prédites avec des différences raisonnables. Dans toutes les configurations du rapport de l'espacement des buses-plaque supérieure diamètre plateforme $L_{j} / D_{c}$ a des effets importants sur les caractéristiques de coussin et $L_{j} / D_{c}=0.1$ peut être considéré comme une valeur critique sur laquelle le coussin commence à exploser et irrégulière avec le temps.

MOTS - CLES:, jet périphérique, jet conique, jet annulaire, coussin d'air.

\footnotetext{
* Received: 8/8/2010, accepted: 24/10/2011 (origional Paper)

+Contact author (iamg_51@yahoo.com)
} 


\section{INTRODUCTION}

Jet flows, as a part of fluid mechanics, concerns many theoretical problems such as stability phenomenon, laminar, turbulent, transition, fluid entrainment and mixing. The jets are utilized in various applications such as propulsion of aircrafts and rockets, burners, mixers, etc. An interaction of the jet with a solid surface is of fundamental importance both for fluid dynamics and heat/mass transfer. Impinging jets are used in many applications such as cooling (electronic component, turbine blades), heating, drying, etc.; Garimella (2000), Trávníček and Peszyński (2002), Yang et al. (1999) Cooper et al. (1993). The jet-induced forces generated on short take off and vertical landing (STOVL) aircraft when in close proximity to the ground can have a significant effect on air craft performance. Special care and concentrated search efforts are done for understanding of the impinging jet flow field for design of efficient (STOVL); Tam (1990), Glass (1968) and Alvi (1999), Donaldson \& Snedeker (1971) Carling \& Hunt (1974), Lamont \& Hunt (1980), Karamcheti et al., (1969), Krothapalli et al.,(1999), Sheplak, and Spina, (1994). The studies mainly emphasized on the mean properties of this flow with most of the measurements limited to mean surface properties, such as pressure distribution on the impingement surface. Jet impingement solid surface at low nozzle-plate spacing are investigated for mass/heat transfer; Lytle and Webb (1994), Chatterjee and Deviprasath (2001). Jet-induced ground effects on a parametric flat-plate model of a hover are studied by Wardwell et al. (1993). Air cushion machines, such as; power augmented ram and hovercraft are supported by the dynamic air cushion formed by air jets injected below the vehicle platform. Numerical simulation of flow emerging from annular-conical nozzle combinations impinging onto a cylindrical cavity is studied by Shuja et al. (2009). A simplified two-dimensional peripheral Jet theory for the equilibrium performance of an air cushion vehicle is investigated by Rogers and John, R. (1973). The proposed theory intends to yield a rapid prediction of the actual flow rate and actual power requirements for an air cushion landing system in the hover condition. Nine specific nozzle configurations were tested to determine whether the theory is able to predict the experimental data. An experimental study of Jet induced pressure distribution under platform in presence of ground effect has been undertaken by Soderlund et al. (2010). They aimed to determine steady state pressure distribution under a static model. Main controlled parameters include the jet thickness and platform height is tested.

The present investigation presents an experimental study of annular-conical air jet impinging normally on a flat plate surface at low nozzle-plate spacing. Measurements of the pressure distributions at impinged plate, model platform, plenum chamber, and jet exit will be conducted. Effects of various parameters on the air cushion pressure behavior like as; jet thickness $t_{j}$, jet angle $\theta_{j}$, nozzle-plate spacing $L_{j}$ and jet velocity $V_{j}$ are studied.

In the literature there may not be any model having the same configuration of the current model. This makes difficulty of comparison the results. It may be useful to use the theories studying peripheral jet air cushion hovering on a rigid surface for 
comparison of the results. The important three theories studying peripheral jet air cushion hovering on a rigid surface are: theory of thin peripheral, exponential theory of air cushion, theory of plenum chamber on a rigid surface. A useful indirect comparison of the experimental result will be tried with Ref(14).

\section{EXPERIMENTAL RIG}

The studied peripheral jet model has a conical-annular convergent nozzle confined by two coaxial walls and ended by plan annular peripheral jet exit of internal diameter $D_{c}$ and its external diameter equal $D_{c}+2 t_{j} \operatorname{cosec} \theta_{j}$, where $t_{j}$ is the constant annular thickness.

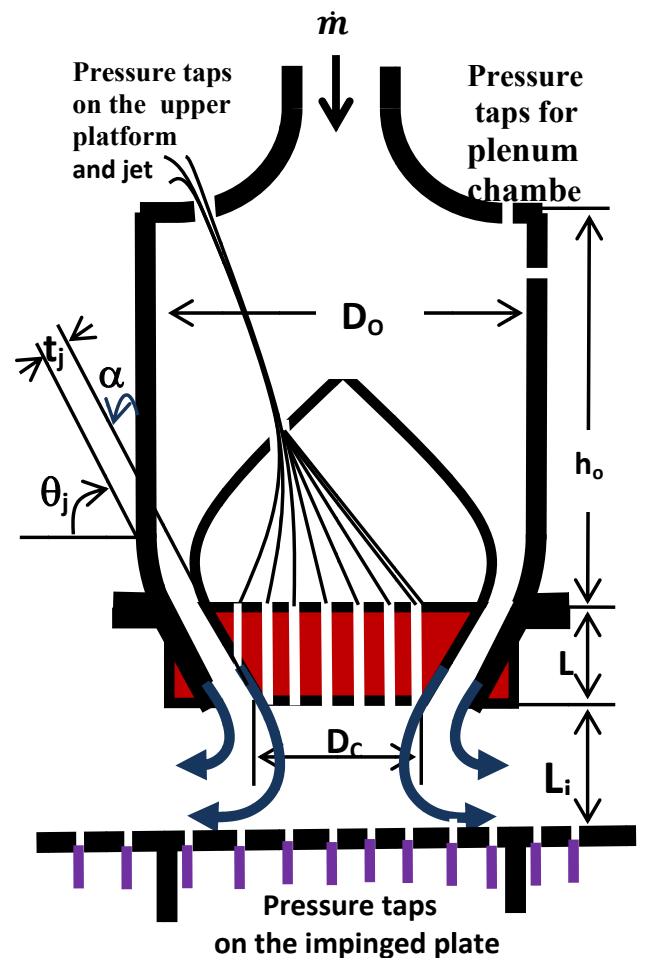

Fig. (1): Sketch of peripheral air jet model of annular conical nozzle positioned in proximity with a flat plate to create air cushioned in between.

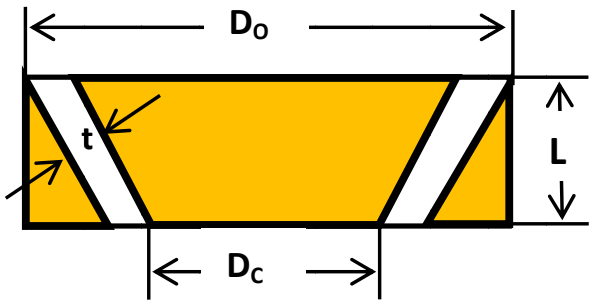

Fig. (2): Sketch of replacement parts

The lower part is a collection of changeable parts in purpose to change $t_{j}, L_{j}$ and $\theta_{j}$ Fig 2.

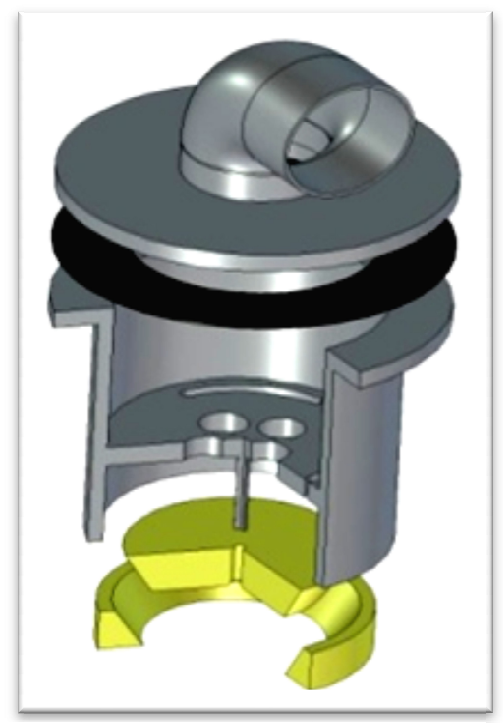

\section{Fig. (3): Real aluminum peripheral air jet model (annular conical axisymmetric nozzle)}

The area surrounded by the plan annular jet and lies in its plane has a diameter $D_{c}$ and will be called "model platform". The model and its sketch of replacement parts are sketched in Fig land Fig. (2) respectively. All model parts are axisymmetric about the same model axis. The model is supplied by air through a top circular inlet. The inlet air is decelerated at a plenum chamber of diameter $D_{0}$ and height $h_{0}$. The plenum 


\section{Ibrahim A. M. Gad}

chamber is ended by the inlet of the annular nozzle. The annular nozzle is convergent having two coaxial walls. The nozzle exit is placed in proximity of an impinged plate. The air cushion region between the impinged plate and the model platform presents the ambient condition of the nozzle.

The real aluminum peripheral air jet model is fabricated with good accuracy from aluminum, steel and wood. The solid work drawing of this model is presented in Fig 3. The impinged plate is fixed on a supported table Fig 4. A vertical smooth rod is fixed on one side of the table. A complex support can be fixed or slid up and down on this rod. This complex support has a ring can be rotated around a horizontal axis Fig 4. The collection of impinged flat plate, its supporting table, complex support and the real aluminum model is presented in Fig 5. A Perspex square plate of length $50 \mathrm{~cm}$ and thickness $3 \mathrm{~mm}$ is pierced by 53 pressure taps which located on the circumference of seven circles of different diameters as shown in Fig 6 and table 1.

Pressure taps also are needed to be pierced on the platform of the model (circular area surrounded by the annular jet).Two wind tunnels were made available to supply the jet model by air with different mass flow rates, Fig 7 (a, b). The nozzle jet exit is kept in the proximity of the flat plate with small, variable nozzle-plate spacing. The two air sources are use to enlarge the range of investigated mass flow rates. The jet pressure is measured using 4 pressure taps just upstream of the nozzle exit and the pressure inside the plenum chamber is measured using 2 pressure taps in the top and side of the plenum chamber Fig.(1).

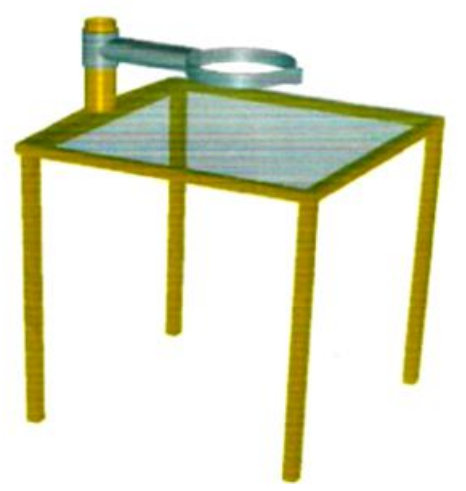

Fig. (4): the conical jet in close proximity with impinged plate fixed on its table.

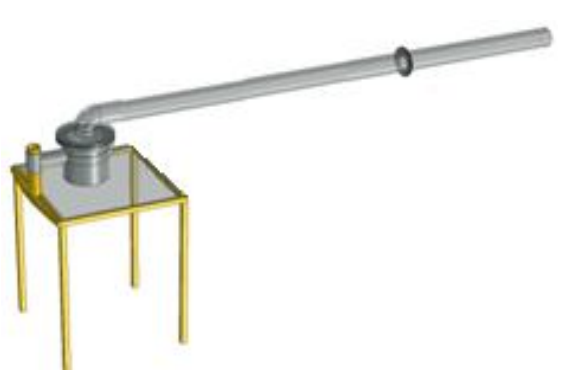

Fig. (5): the collection of impinged flat plate and its supported table as well as the real aluminum model

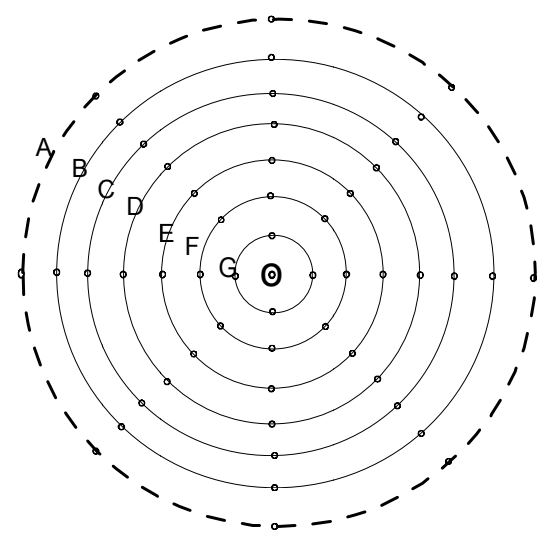

Fig. (6): Map of pressure taps locations on the square impinged plate. 
Tables (1): pressure taps circles.

\begin{tabular}{|c|c|c|}
\hline Taps Circle & D cm & $\mathrm{N}^{\mathrm{o}}$ of taps \\
\hline A & 25.2 & 8 \\
\hline B & 21.6 & 8 \\
\hline C & 18 & 8 \\
\hline D & 14.4 & 8 \\
\hline E & 10.8 & 8 \\
\hline F & 7.2 & 8 \\
\hline G & 3.6 & 4 \\
\hline O & 0 & 1 \\
\hline
\end{tabular}

Each of the two testing systems Figs 7 (a, and b) consists of an air source (centrifugal fan), plenum chamber ended by conical peripheral air jet prepared to work with variable annular thickness and different nozzle-plate spacing. One system is prepared to investigate the effects of various jet parameters like as: annular thickness $t_{j}$, jet angle $\theta_{j}$, nozzle-plate spacing $L_{j}$ and jet velocity $V_{j}$. Note that jet velocity is dependent variable $V_{j}=f\left(\theta_{j}\right.$, $\left.t_{j}, L_{j}, L_{j} / D_{c}\right)$

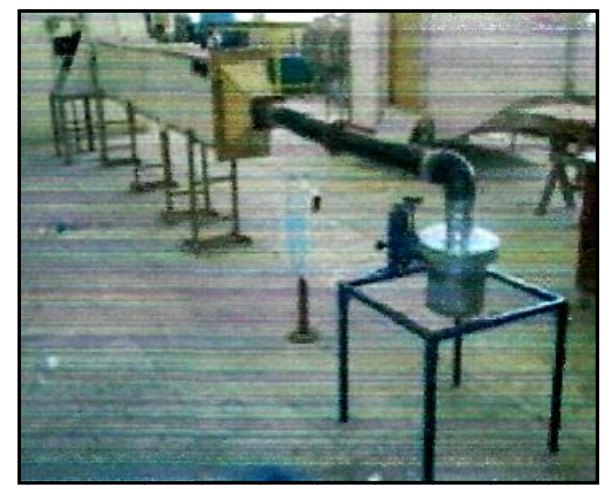

Fig. (7-a): First available wind tunnel is used in the testing for higher mass flow rate range $\dot{m}(0.5: 1.2 \mathrm{~kg} / \mathrm{sec})$

The air cushion pressure distribution was measured as a function of annular thickness and the jet angle $\theta_{j}$ where $\theta_{j}=\pi / 2-\alpha_{j}$ and $\alpha_{j}$ is the conical angle of the jet.
The time averages gauge pressure distributions $P_{c}(x, y)$ at impinged plate, model platform of diameter $D_{c}$ and nozzle exit pressure $P_{j}$ and plenum chamber pressures $P_{o}$ are measured.

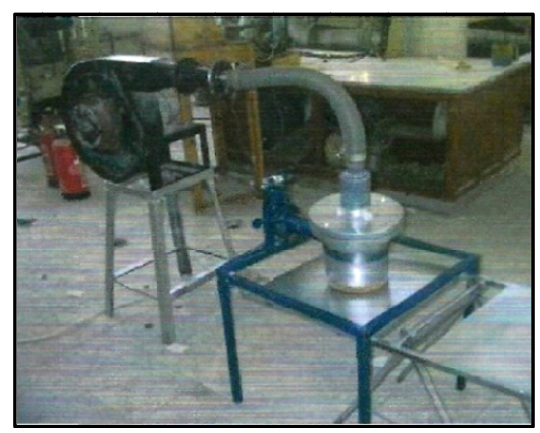

Fig. (7-b): Second available wind tunnel is used in the testing for lower mass flow rate range $\dot{m}(0.2: 0.55 \mathrm{~kg} / \mathrm{sec})$

\section{MEASURMENTS \\ AND INSRUMENTATION}

The conical peripheral air jet impinging on the flat plate is tested under different configurations of jet thickness, conical angle, nozzle-plate spacing and jet velocity. The jet is positioned in proximity of the plate to create an air cushion of relatively high pressure. For each studied case the static pressure distributions are measured at the two parallel plate surfaces; (1) the impinged plate surface prepared by 53 pressure taps and (2) the upper circular platform surface prepared by (19: 37) pressure taps. The plenum pressure $P_{0}$ and the jet pressure $P_{j}$ are measured by averaging the readings of the corresponding 4 and 8 pressure taps, respectively.

This experimental study has been carried out in Mechanical Power Eng. Department, Fluid Mech. Laboratory Zagazig University. 


\section{Ibrahim A. M. Gad}

The annular jet thickness $t_{j}$ and jet conical angle $\theta_{j}$ are varied to obtain different model configurations. The models which are tested in these studies are described in table 1.

Table (2): tested models

\begin{tabular}{|c|c|c|}
\hline Model & $\theta_{j}^{o}$ & $\mathrm{t}_{\mathrm{j}} \mathrm{mm}$ \\
\hline 1 & 15 & 5 \\
\hline 2 & 30 & 5 \\
\hline $3,4,5$ & 45 & $3,5,8$ \\
\hline 6,7 & 55 & 9,7 \\
\hline $8,9,10$ & 90 & $5,10, \infty$ \\
\hline
\end{tabular}

The air mass flow rate is controlled by a gate with circular cross sectional area, has a diameter of $150 \mathrm{~mm}$. The gate rotates about a vertical axis to change the opening pass of the air. The gate is calibrated by Pitot - static tube. Two electronic and water manometers are used for pressure measurements. The standard accuracy of the measurements reaches $0.04 \mathrm{~mm} \mathrm{H}_{2} \mathrm{O}$. To change the jet gap with the stationary plate a mechanical mechanism are used to raise and down the whole model on its table. To change the jet thickness and its direction angle, the lower part containing the jet thickness and direction is changeable. Eight models with different jet thickness and direction were manufactured - see table 2 .

\section{RESULTS AND DISCUSSIONS}

The time average measured gauge pressure distributions on the impinged plate and the model platform are indicated as $P_{c} \mathrm{~mm} \mathrm{H}_{2} \mathrm{O}$. The absolute pressure values will be indicated when it is needed. All models in table 1 are tested. The results recorded in this paper are those necessary to clarify the flow characteristics. The jet velocity $V_{j}$ is ranged from 14 to $55 \mathrm{~m} / \mathrm{s}$ in all tested cases. The nozzle-plate spacing strongly affects the ratio $P_{c} / P_{o}$. The results show that, $P_{c} / P_{o}$ equal 1 nearly. The small $P_{c} / P_{o}$ means that the flow is incompressible. The pressure distributions on impinged plate and the model platform were measured as function of the air jet velocity, the nozzle-plate spacing, the jet thickness, and the conical jet angle. Figs. 8 (a, b) show comparisons between measured time averaged pressure distributions on the impinged plate and on the model platform, respectively. Figs. 9 (a, b, c, d, e, f, g, h) present the results of measured pressure distribution for $\theta=30^{\circ}$ for; $\left(t_{j}, L_{j}\right)=(7,3),(7,10),(7$, $20),(7,25),(9,3),(9,10),(9,20),(9,25)$, respectively.

Fig 10 presents the space time average pressure $\overline{\mathrm{P}_{\mathrm{c}}}$, over the impinged plate for different nozzle-plate spacing and different jet velocities. Figs 11 (a, b, c... 1) represent the variation of measured pressures $\mathrm{P}_{\mathrm{o}}, \mathrm{P}_{\mathrm{c}}$ and $\mathrm{P}_{\mathrm{j}}$ for cone angle $\theta=45^{\circ}$ and different values of jet thickness and nozzle-plate spacing, respectively. These results show that at low values of nozzle-plate spacing $L_{j} / D_{c}<0.1$ the flow is axisymmetric and the measured time averaged gauge pressure $P_{c}(x, y)$ at the model platform is constant. Some negligible decrease near the internal circumference of the jet is noticed. While at the impinged plate the measured gauge pressure $P_{c}$ shows three distinguished regions; 1) at inner central region of diameter $D<D_{1}, D_{1}=$ $\mathrm{D}_{\mathrm{c}}(1-2 \mathrm{~L} / \tan \theta)$ the gauge pressure $\Delta P_{c}$ is nearly constant, 2) at the outer region of diameter $D>D_{c}$ the gauge pressure $P_{c}$ increases and tends to 
approach to zero by increasing the diameter and 3) at intermediate region of diameter $D_{1}<D<D_{c}$ a negative gauge pressure $P_{c}$ is noticed after a sudden drop of its positive value in central region. The region of negative measured time averaged pressure $P_{c}$ diminishes by increasing $\mathrm{L}_{\mathrm{j}} / \mathrm{D}_{\mathrm{c}}$ until it disappears at $L_{j} / D_{c}=0.1$ nearly. At high nozzle-plate spacing $\mathrm{L}_{\mathrm{j}} / \mathrm{D}_{\mathrm{c}}>0.1$ the measured time average pressure $\mathrm{P}_{c}$ on the impinged plate and model platform is begun to deregulate from its axisymmetric shape which was noticed at low values of $\mathrm{L}_{\mathrm{j}} / \mathrm{D}_{\mathrm{c}}<0.1$. This irregularity increases by increasing $L_{j} / D_{c}$. The measured value of $\mathrm{P}_{\mathrm{c}}$ is noticed to be varied during the time of measurements. The results show also that $\mathrm{P}_{\mathrm{j}}$ nearly equal $\mathrm{P}_{\mathrm{c}}$ and that the range of $V_{j}$ is incompressible due to the proximity of jet and plate for all studied cases. For all presented cases the measured gauge pressures of $\mathrm{P}_{\mathrm{o}}, \mathrm{P}_{\mathrm{j}}$ and $\mathrm{P}_{\mathrm{c}}$. The results show that the measured $\mathrm{P}_{\mathrm{o}}, \mathrm{P}_{\mathrm{j}}$ and $\mathrm{P}_{\mathrm{c}}$ increase by increasing jet velocity $V_{j}$ or decreasing $L_{j}$. It is seem that their values tend to certain maximum values. Fig 9 presents the measured pressure in case of $\theta_{i}=30^{\circ}, t_{i}=9 \mathrm{~mm}$ and $L_{j}=$ $9 \mathrm{~mm}$; at impinged plate and model platform. Fig 10 (a through $\mathrm{f}$ ) present the gauge pressure differences measured at the impinged plate for the cases $\theta=30^{\circ}$ described in table 3 .

\section{(a) Measurements Uncertainty}

The method applied here for calculating the uncertainty of measurements is guided by Sun, Z. et al. (2008), Zhang, H. et al. (2006) and Bell, S. (1999). Bell, S. (1999) briefed the steps of calculation as; 1) Decide what you need to find out from your measurements. Decide what actual measurements and calculations are needed to produce the final result 2) Carry out the measurements needed 3) Estimate the uncertainty of each input quantity that feeds into the final result. Express all uncertainties in similar terms 4) decide whether the errors of the input quantities are independent of each other. 5) Calculate the result of your measurement including the calibration) 6) Find the combined standard uncertainty from all the individual aspects 7) Express the uncertainty in terms of a coverage factor together with a size of the uncertainty interval, and state a level of confidence 8) Write down the measurement result and the uncertainty, and state how you got both of these. In this work the jet velocity and pressure are the output of these measurements. The apparatus used are electronic manometer; thermocouples, barometer and Pitot-static tub are used.

The calculated uncertainty of measured gauge pressure $\mathrm{UP}_{\mathrm{c}}=2.1 \%$ and the uncertainty of measured velocity are $U V_{j}=5.2 \%$.

Table (3): description of Fig 10 (a through f) $\theta_{j}=30^{\circ}$

\begin{tabular}{|c|c|c|c|}
\hline Fig 10 & $t_{j} \mathrm{~mm}$ & $L_{j} \mathrm{~mm}$ & $D_{c} \mathrm{~mm}$ \\
\hline 5-a & 0.7 & 1 & 11.5 \\
\hline 5-b & 0.7 & 10 & 11.5 \\
\hline 5-c & 0.7 & 20 & 11.5 \\
\hline 5-d & 0.7 & 25 & 11.5 \\
\hline 5-e & 0.9 & 1 & 11 \\
\hline 5-f & 0.9 & 10 & 11 \\
\hline 5-g & 0.9 & 20 & 11 \\
\hline 5-h & 0.9 & 25 & 11 \\
\hline
\end{tabular}


Experimental Investigation of Conical Peripheral Jet Normally Impinging on a Flat Plate Ibrahim A. M. Gad

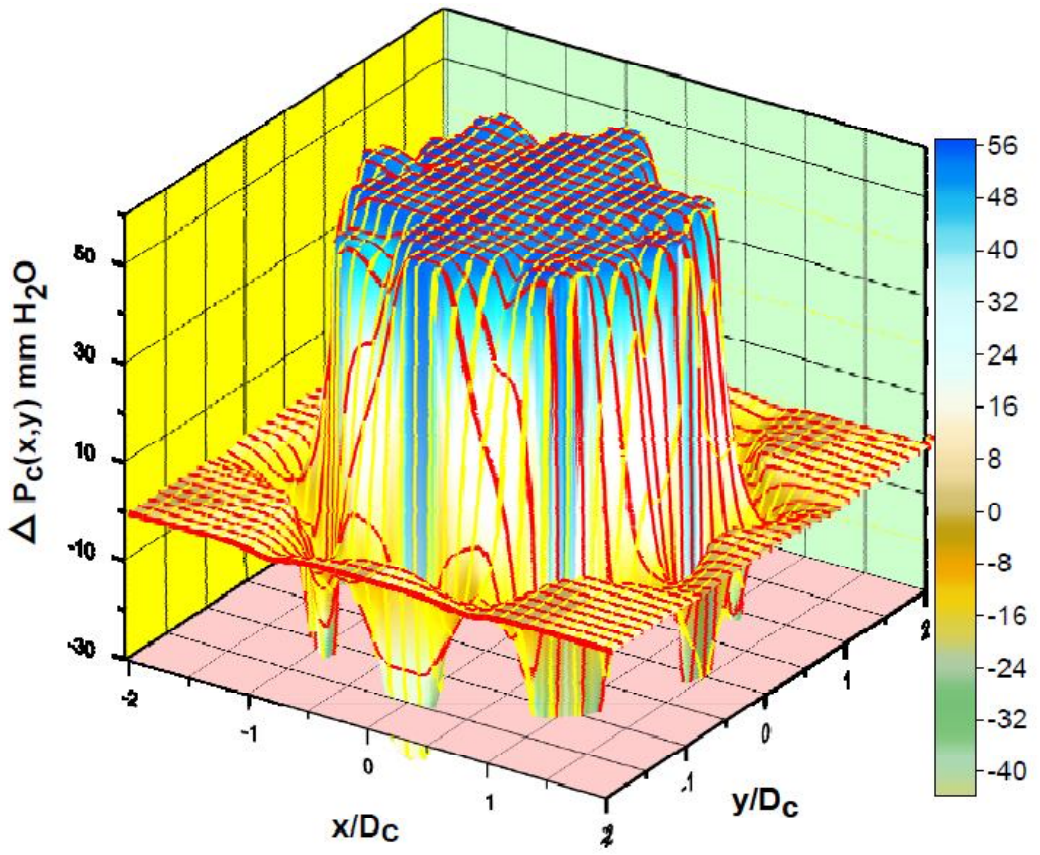

(a) - Measured time averaged gauge pressure distribution $P_{c}(x, y)$ at impinged plate

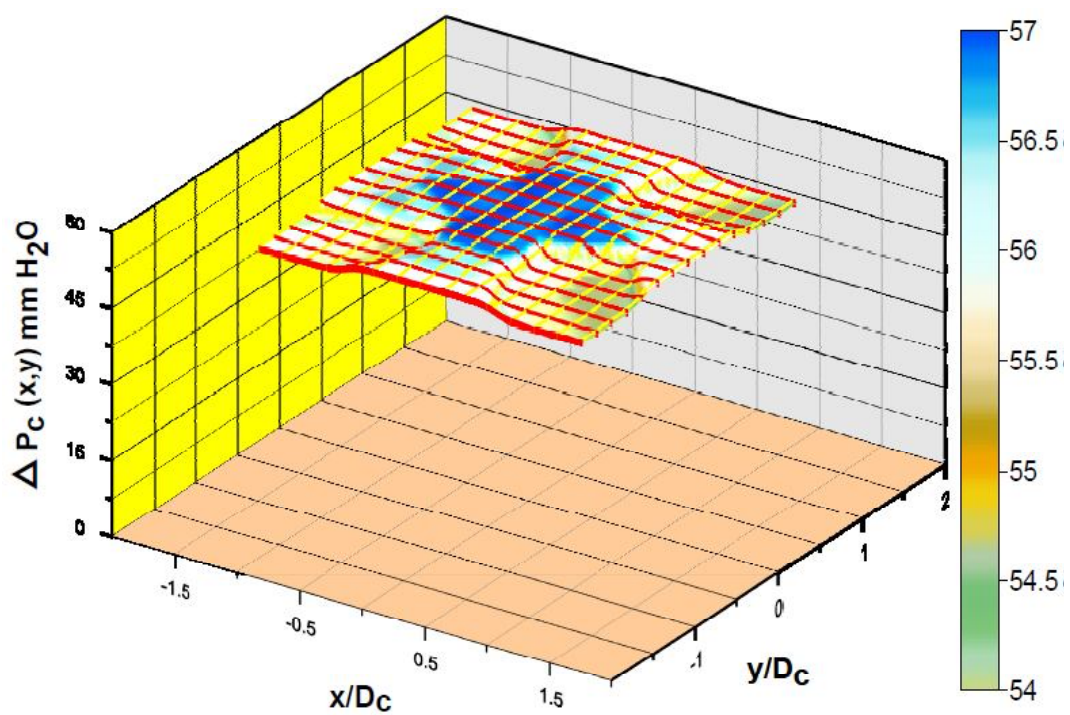

(b) Measured time averaged gauge pressure distribution $\boldsymbol{P}_{\boldsymbol{c}}$ at model platform Fig. (8): measured time averaged gauge pressure in case of $\theta_{o}=30^{\circ}, t_{j}=$ $9 \mathrm{~mm}$, and $L_{j}=9 \mathrm{~mm}$ (a) impinged plate \& (b) model platform 
Vol.14, No. 1

4. 3. Cases Studied $\theta_{j}=30^{\circ}$ for Different Values of $t_{j}, L_{j}$

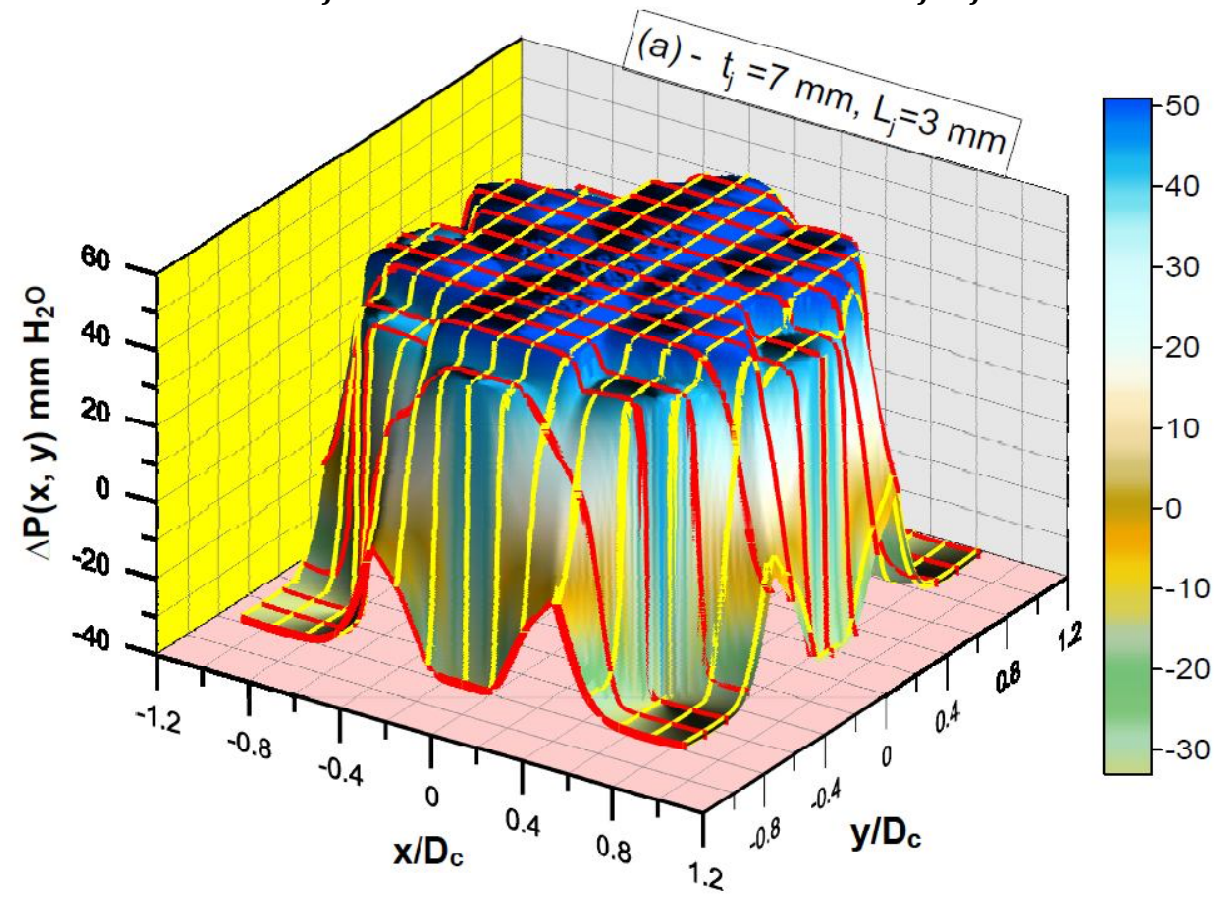

$\mathrm{a}-\mathrm{t}_{\mathrm{j}}=7 \mathrm{~mm}, \quad \mathrm{~L}_{\mathrm{j}}=3 \mathrm{~mm}$

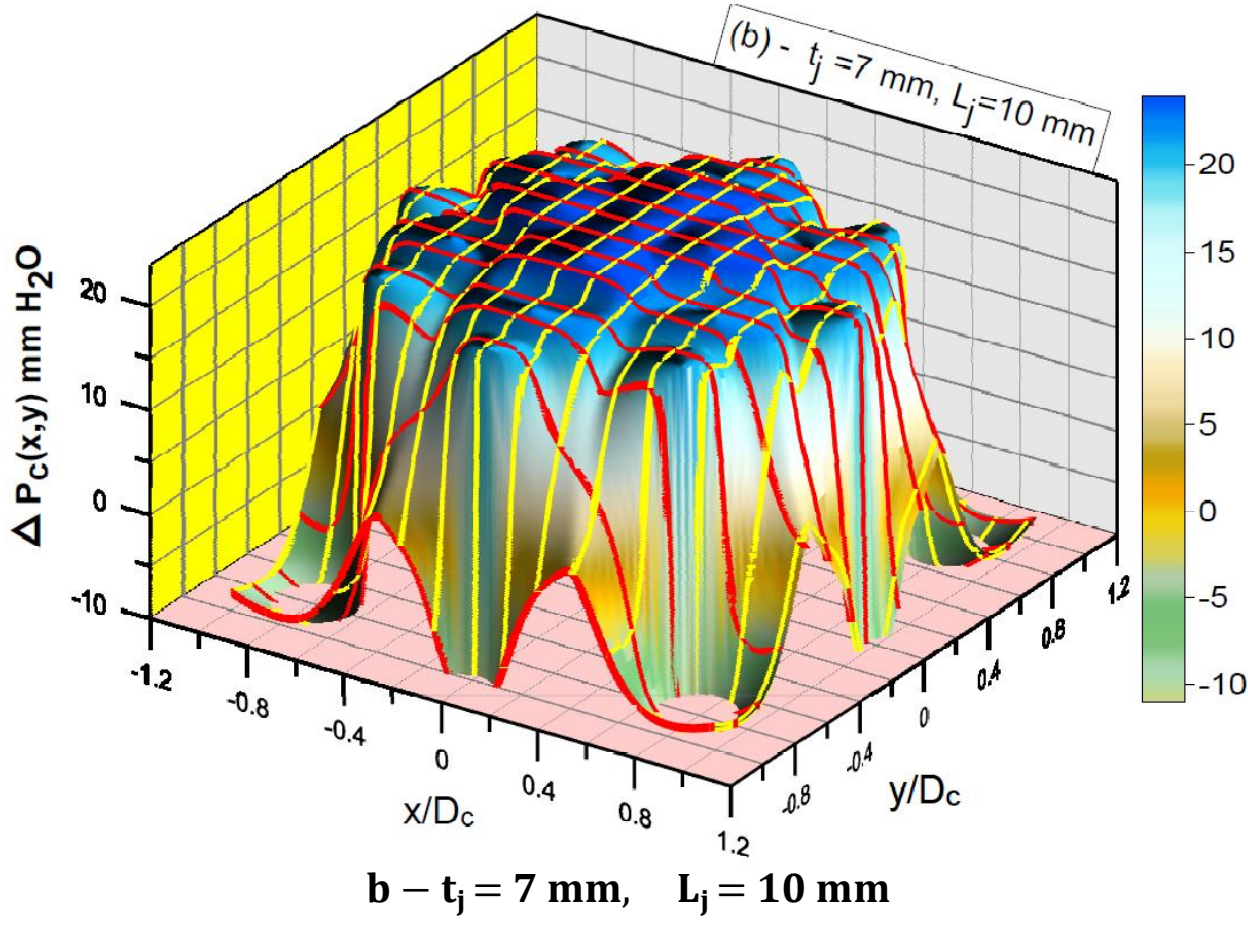


Experimental Investigation of Conical Peripheral Jet Normally Impinging on a Flat Plate Ibrahim A. M. Gad
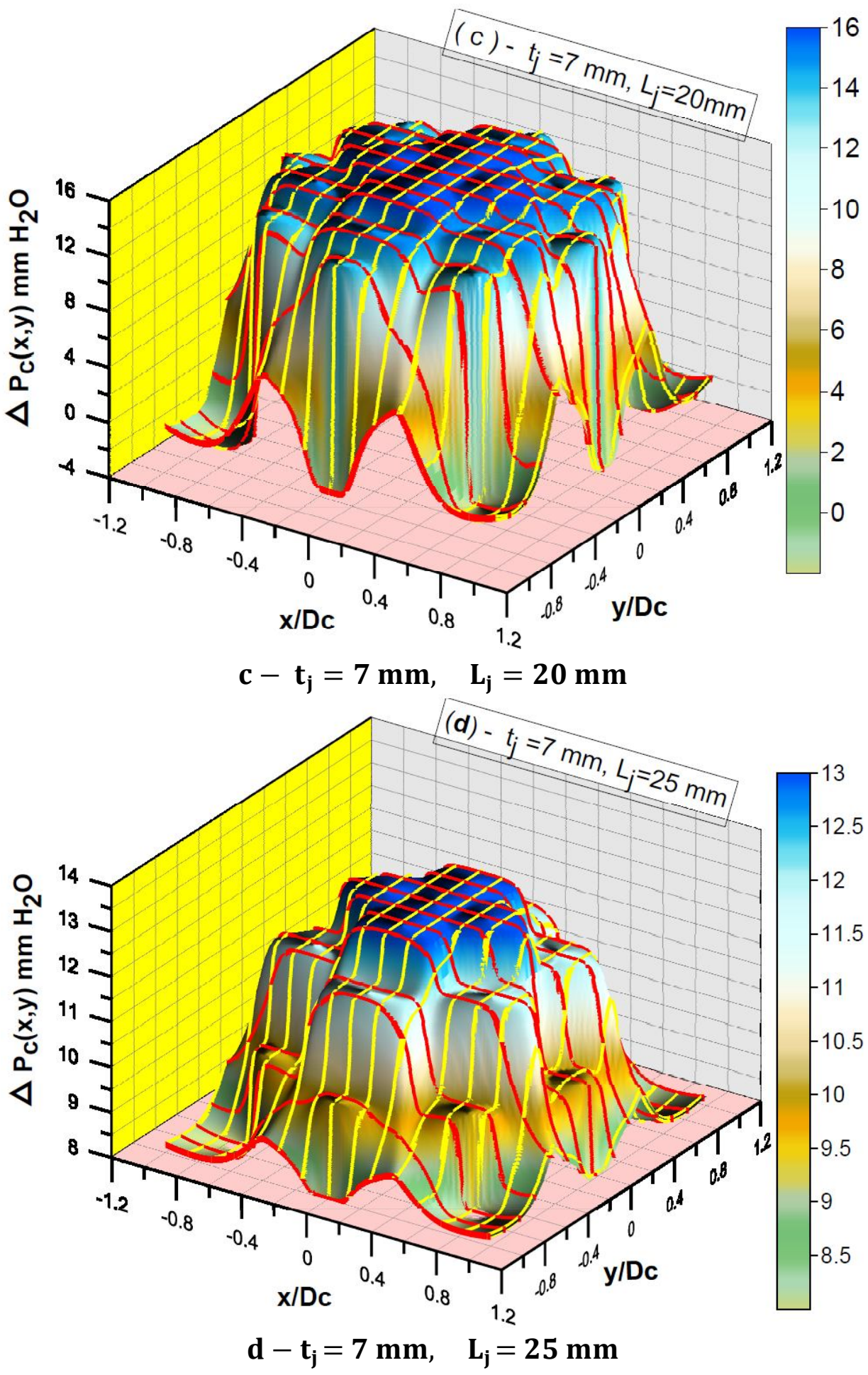
Vol.14, No. 1
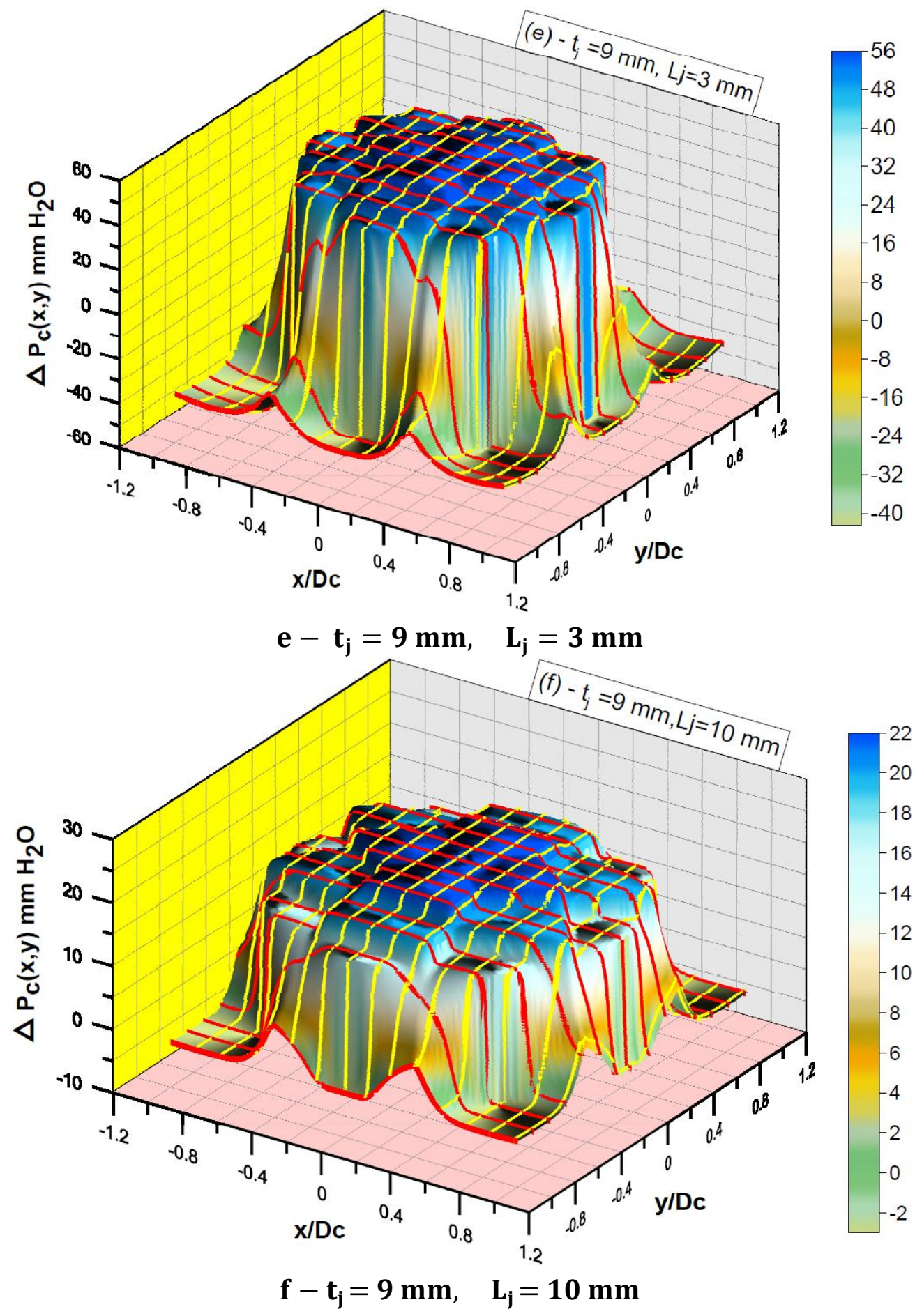
Experimental Investigation of Conical Peripheral Jet Normally Impinging on a Flat Plate Ibrahim A. M. Gad
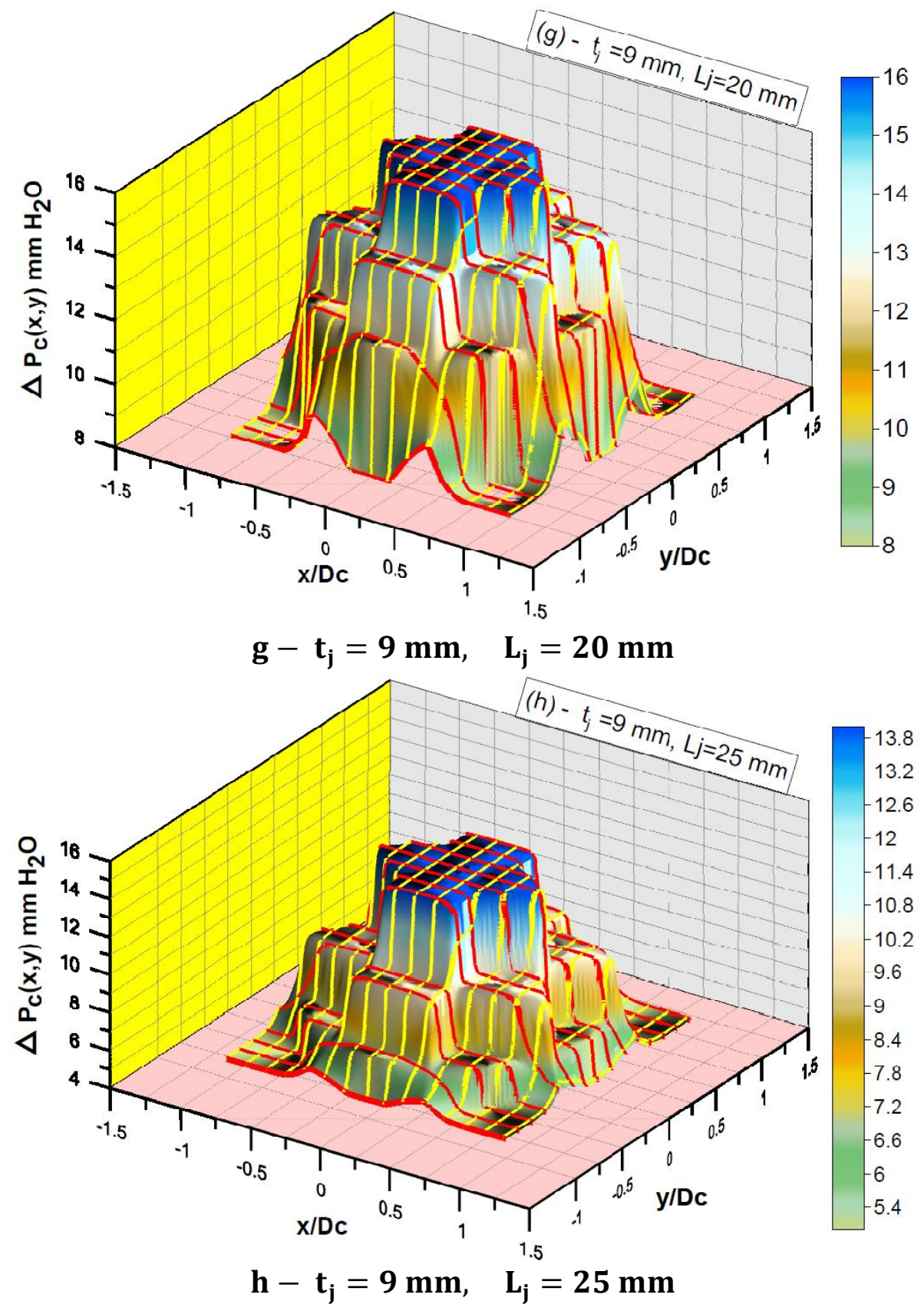

Fig. (9): Cases studied $\theta=30^{\circ}$ and different

$$
\left(t_{j}, L_{j}\right)=\left[\begin{array}{llll}
7,3 & 7,10 & 7,20 & 7,25 \\
9,3 & 9,10 & 9,20 & 9,25
\end{array}\right]
$$


Vol.14, No. 1

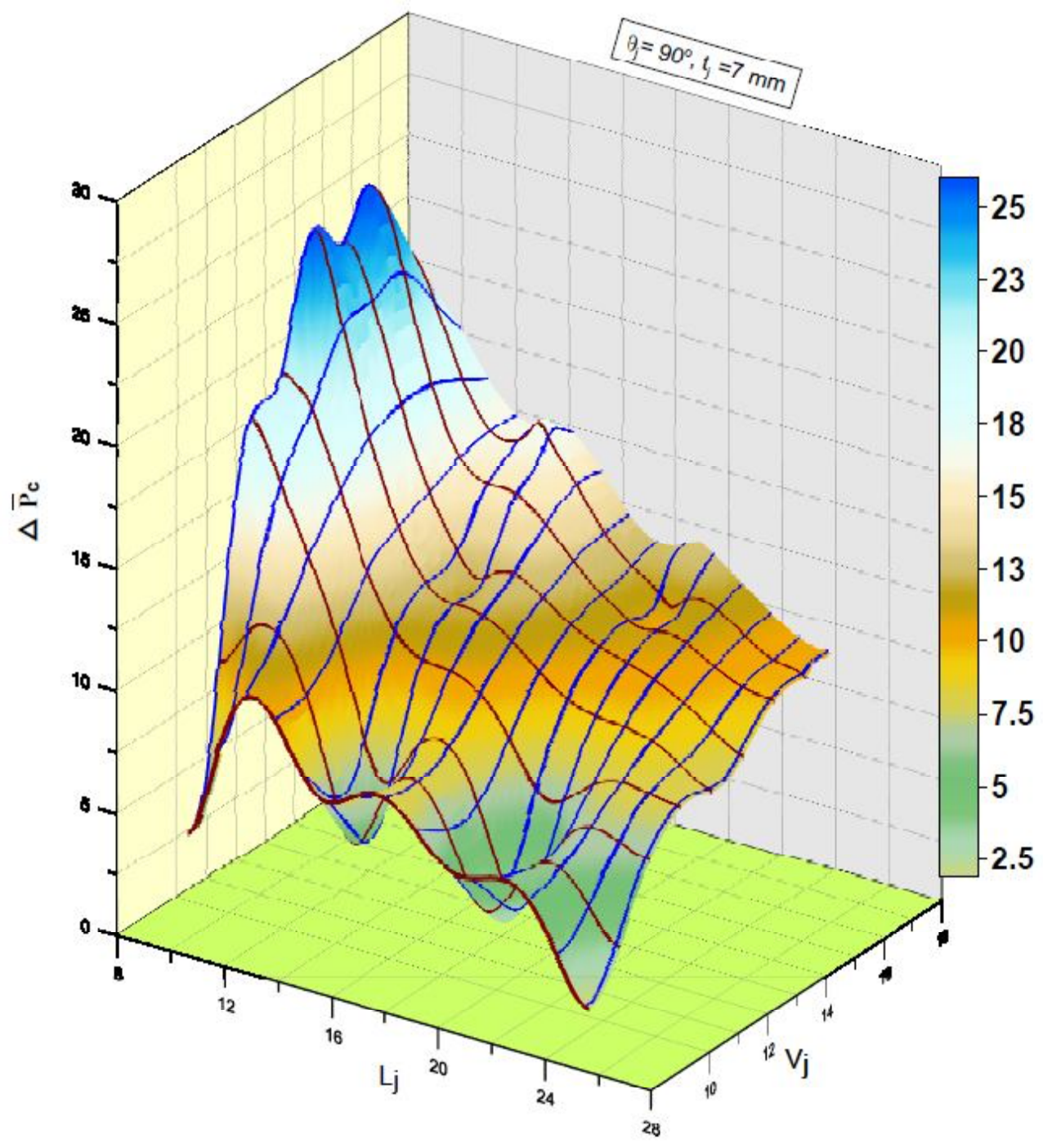

Fig. (10): Space time averaged pressure $\overline{P_{c}}$ measured over impinged plate for various Nozzle-plate spacing $L_{j}$ and various gap jet velocities $V_{j}$ 
Experimental Investigation of Conical Peripheral Jet Normally Impinging on a Flat Plate Ibrahim A. M. Gad

4. 3. Cases Studied $\theta_{j}=45^{\circ}$ for Different Values of $t_{j}, L_{j}$

Gauge pressure in $\mathrm{mm} \mathrm{H}_{2} \mathrm{O}$

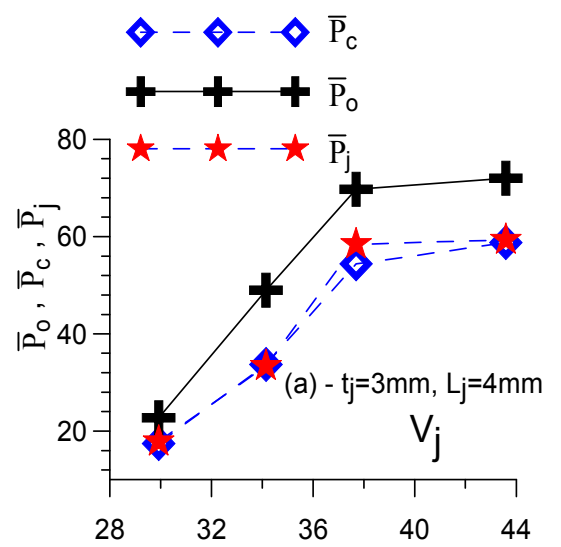

(a) $-t_{j}, L_{j}=3,4$

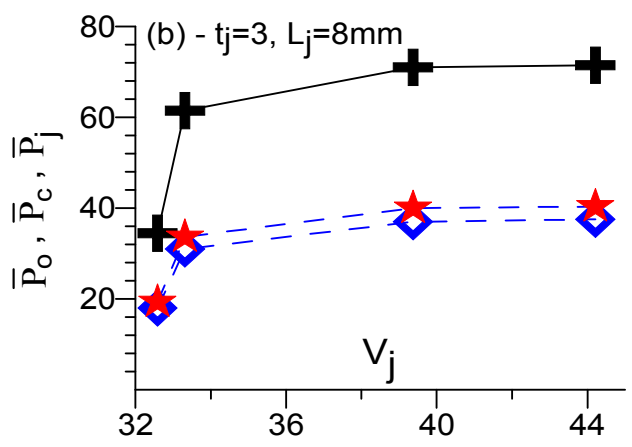

(b) $-t_{j}, L_{j}=3,8$

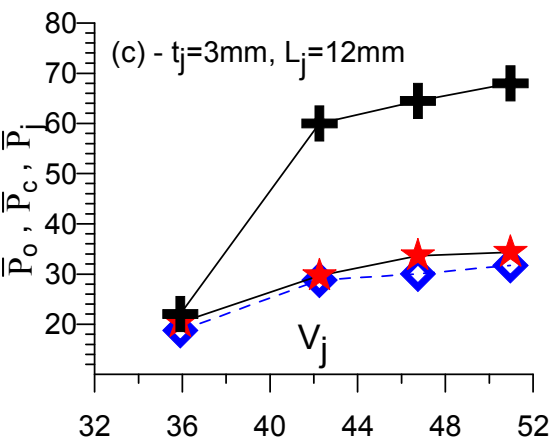

(c) $-t_{j}, L_{j}=3,12$

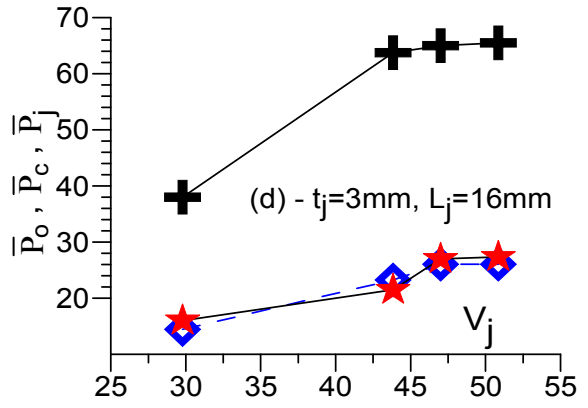

(d) $-t_{j}, L_{j}=3,16$

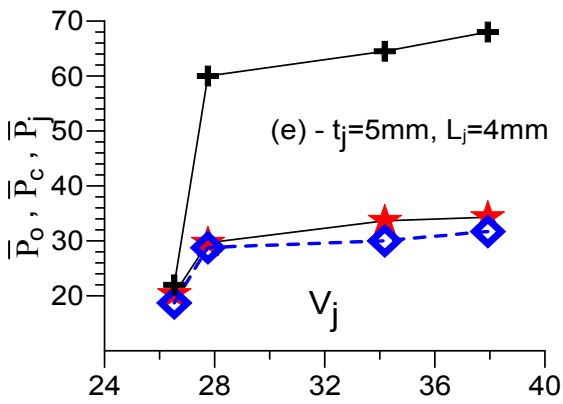

(e) $-t_{j}, L_{j}=5,4$
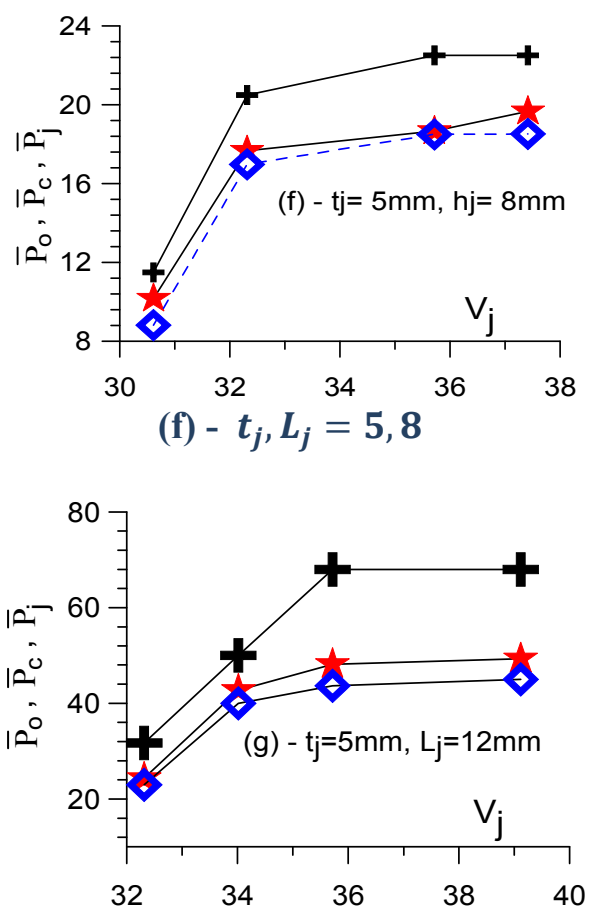

(g) $-t_{j}, L_{j}=5,12$ 


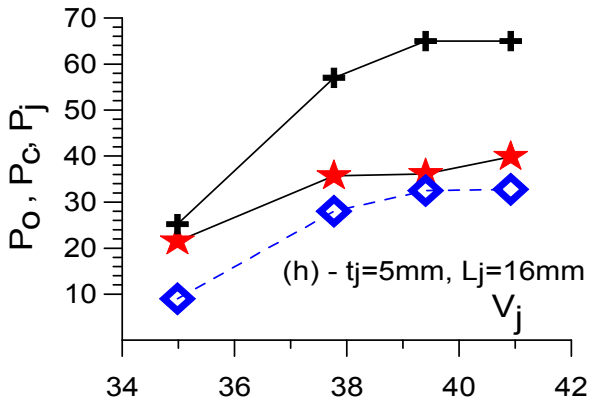

(h) $-t_{j}, L_{j}=5,16$

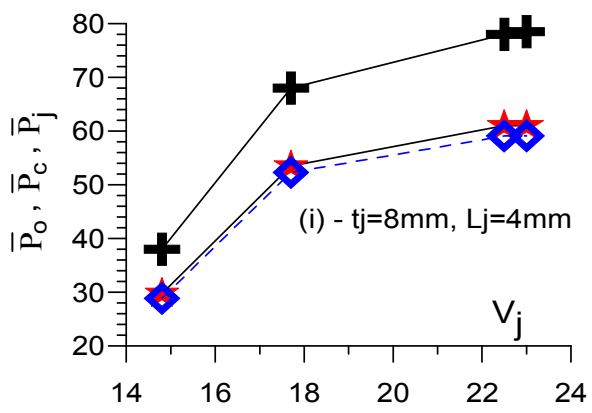

(i) $-t_{j}, L_{j}=8,4$

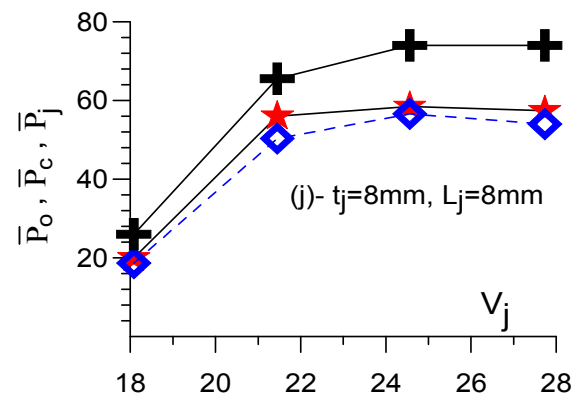

(j) ) $-t_{j}, L_{j}=8,8$

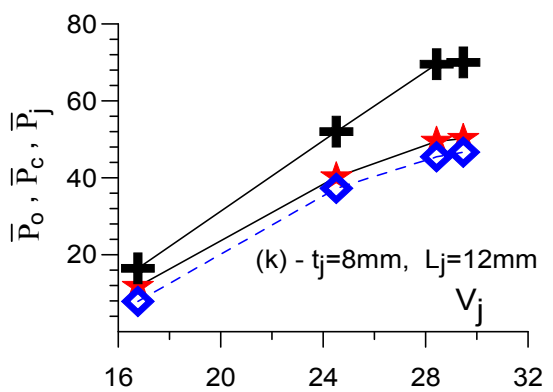

(k) ) $-t_{j}, L_{j}=8,12$

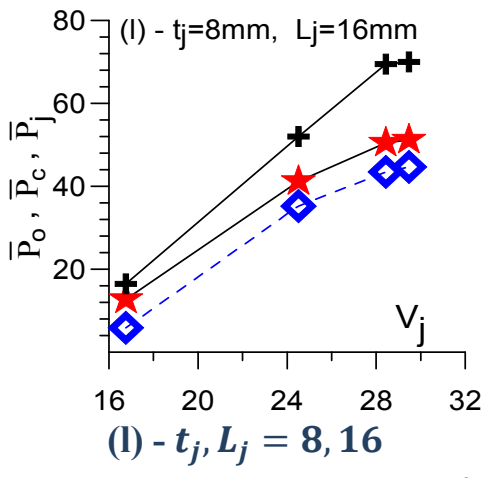

Fig. (11): Cases of jet angle $\theta=45^{\circ}$ for different $\boldsymbol{t}_{\boldsymbol{j}}$ and $\boldsymbol{L}_{\boldsymbol{j}}$ in matrix form

$$
\left(t_{j}, L_{j}\right)=\left(\begin{array}{cccc}
3,4 & 3,8 & 3,12 & 3,16 \\
5,4 & 5,8 & 5,12 & 5,16 \\
8,4 & 8,8 & 8,12 & 8,16
\end{array}\right)
$$

\section{(b) Exponential Theory Analysis}

There are a number of theories for predicting the performance of peripheral jet systems. Among them, the so-called "exponential theory" is one of the most commonly used. In this theory, it is assumed that from the outlet of the nozzle to the point of ground contact, the jet maintains its thickness as well as its circular path, and that the air is inviscid and incompressible. The total pressure $p_{o}$ is assumed to be constant across the jet with a static pressure gradient within it. The distribution of static pressure $p$ across the jet must satisfy the boundary conditions, that is, $p=0$ at the outside and $p=p_{c}$ at the cushion side. Digges (1973) introduced a power-height parameter $C_{h d}$ involves all the physical variables in the power problem. Thus $C_{h d}$ serves as a good measure for the relative power requirements of competing nozzle configurations as:

$$
\begin{gathered}
C_{h d}=550 H P_{\text {air }} / K \\
K=144 D_{0}\left(2 g_{c} / \rho\right)^{1 / 2}\left(P_{c}-P_{a}\right)^{3 / 2} \\
H P_{\text {air }}=\frac{144 Q_{n}\left(P_{o}-P_{a}\right)}{550}
\end{gathered}
$$




\section{Ibrahim A. M. Gad}

The exponential theory is used here to calculate the power-height parameter $C_{h d}$ and from the present measured data $C_{h d}$ is estimated. Fig 12 makes a comparison between $C_{h d}$ calculated by the exponential theory and its estimated values from present experimental data and the measured data by Rogers (1973). The deviation between the present and Rogers's experimental results shown in Fig 12 are due to the two completely different configurations. While the deviation of present experimental results than the predicted by the exponential theory is due to lot assumptions in the theory.

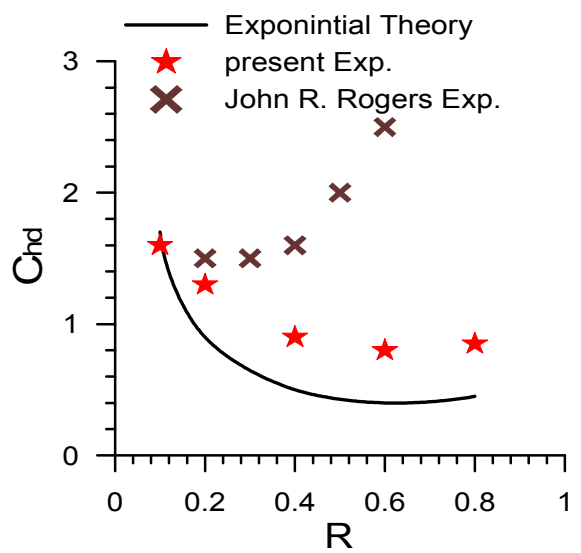

Fig. (12): Predicted and experimentally estimated power-height parameter versus cushion to total pressure ratio

\section{CONCLUSIONS}

A new geometric configuration peripheral air jet model of annular conical convergent nozzle positioned in proximity with a flat plate to create air cushion is investigated experimentally. In the literature there may not be any model having the same configuration of the current model. Therefore the results of experimental investigation conducted by
Digges (1973) on a rectangular peripheral jet opened by distributed number of slots conducted by Digges (1973) as well as the exponential theory calculation is used for comparison with the present experimental results. The power-height parameter $C_{h d}$ (introduced by Digges (1973)) serves as a good measure for the relative power requirements of competing nozzle configurations is used for comparison. For annular conical peripheral jet configurations it can be concluded that:

[1] The ratio of nozzle-plate spacing to upper platform diameter $L_{j} / D_{c}$ has strong effects on cushion characteristics,

[2] The ratio $L_{j} / D_{c}=0.1$ may be considered as a critical value over which the closed air cushion begins to explode producing irregular periodicity with time.

[3] The time and space averaged values $\overline{\mathrm{P}}_{\mathrm{o}}, \overline{\mathrm{P}}_{\mathrm{j}}, \overline{\mathrm{P}}_{\mathrm{c}}$ increase by increasing $t_{j}$ or/and decreasing $L_{j}$,

[4] The experimental results of the powerheight parameter exhibits the same trend as its predicted values by exponential theory with reasonable differences,

[5] The power-height parameter is sensitive to the peripheral jet configurations,

[6] The optimal range pressure ratio $R=P_{c} / P_{o}$ may be ranged from $(0.3$ to $0.8)$.

\section{FUTURE WORK:}

In future we will use all available data for the validation of some suitable turbulence model in solving this type of flow to benefit the advantage of CFD. 


\section{REFRENCES:}

1- Alvi, F S. and Iyer, K. G., (1999), "Mean and unsteady flow field properties of supersonic impinging jets with lift plates", AIAA Paper 99-1829 to be presented at the 5th AIAA/CEAS Aero - acoustic Conference.

2- Bell, S., (1999), "A Beginner's

Guide to Uncertainty of Measurement" Measurement Good Practice Guide No. 11 (Issue 2) ISSN 1368-6550.

3- Carling, J. C., and Hunt, B.L., (1974), "The Near Wall Jet of a Normally Impinging, Uniform, Axisymmetric, Supersonic," J. Fluid Mech., 66, pp 159-176.

4- Chatterjee, A., and Deviprasath, L. J., (2001), "Heat Transfer in Confined Laminar Axisymmetric Impinging Jets at Small Nozzle-Plate Distances: The Role of Upstream Vorticity Diffusion Number", Heat Transfer A, vol. 39, no. 8, pp. 777-800.

5- Cooper, D., Jackson, D. C., Launder, B. E., and Liao, G. X., (1993), "Impinging Jet Studies for Turbulence Model Assessment - I: Flow-Field Experiments, Int. J. Heat Mass Transfer, vol. 36, pp. 2675-2684.

6- Digges, K. H., (1971), "Theory of an Air Cushion Landing System for Aircraft", Technical Report AFFDL TR71-50 Wrighl-Patterson Air Force Base, Ohio; Air Force Flight Dynamics Laboratory, I.

7- Donaldson, C., Du, P., Snedeker, R. S., (1971), "A Study of Free Jet Impingement. Part 1. Mean Properties of Free and Impinging Jets", J. Fluid Mech., 45, pp 281-319.

8- Fujimoto, H., Takahashi, O., Ishii, R., Hatta N., (1991), "Numerical Fluid Dynamics Symposium", 5th, Tokyo, Japan, Dec. 19-21, , Proceedings (A93-
38126 15-34), p. 637-640.

9- Garimella, S.V., (2000), "Heat transfer and flow fields in confined jet impingement", Annual Review of Heat Transfer XI, pp 413-494.

10- Glass, D. R., (1968), "Effect of acoustic feedback on the spread and decay of supersonic jets" AIAA, Vol. 6, No. 6, pp 1890-1897.

11- Karamcheti, K., Bauer, A.B.,

Shields, W.L., Stegen, G.R., and Woolley, J.P., (1969), "Some Features of an Edge Tone Flow Field", NASA SP 207, pp275 - 304.

12- Lamont, P.J., and Hunt, B.L., (1980), "The Impingement of Under expanded Axisymmetric Jets on Perpendicular and Inclined Flat Plates," Journal of Fluid Mechanics, Vol. 100, pp 471- 511.

13- Lamont, P.J., and Hunt, B.L., (1980), "The Impingement of Under expanded Axisymmetric Jets on Perpendicular and Inclined Flat Plates," Journal of Fluid Mechanics, Vol. 100, pp 471- 511.

14- Lytle, D., and Webb, B. W., (1994), "Air Jet Impingement Heat Transfer at Low Nozzle-Plate Spacings", Int. J. Heat Mass Transfer, vol. 37, no. 12, pp. 1687-1697.

15- Rogers, J. R., (1973), “Two-

Dimensional Air Cushion Landing System Peripheral Jet Configuration Study", Master's thesis Air Force Flight Dynamics Laboratory Wright-Patterson AFB, Ohio 45433.

16- Sheplak, M., and Spina, E.F., (1994), "Control of high-speed impinging-jet resonance", AIAA Journal, Vol.32, No.8, pp1583-1588.

17- Shuja, S.Z., Yilbas, B.S., Khan, S. A., (2009), "Flow emerging from annular-conical nozzle combinations 
and impinging onto a cylindrical cavity", International Journal of Thermal Sciences 48 pp. 975-984.

18- Soderlund, R., Konstantin, K. M., (2010), International Journal of Vehicle Design, Volume 53, Number 3, pp. 133148.

19- Sun, Z., Zhang, H., Zhou, J., (2008), "Evaluation of uncertainty in a vortex flow meter measurement" Measurement 41 (2008) 349-356

20- Tam, C. K. W., Ahuja, K.K., (1990), "Theoretical model of discrete to degeneration by impinging jets", J. Fluid Mech., Vol. 214, pp 67-87.

21- Trávníček, Z., Peszyński, K., Hošek, J., Wawrzyniak, S., (2002), "Aerodynamic and mass transfer characteristics of an annular bistable impinging jet with a fluidic flip-flop control", International Journal of Heat and Mass Transfer.

22- Trávníček, Z., Peszyński, K., Hošek, J., Wawrzyniak, S., (2002), "Aerodynamic and mass transfer characteristics of an annular bistable impinging jet with a fluidic flip-flop control", International Journal of Heat and Mass Transfer.

23- Wardwell, D. A., Hange, C., Kuhn, R. E., and Stewart, V.R., (1993) "Jet-Induced Ground Effects on a Parametric Flat- Plate Model in Hover", NASA TM 104001.

24- Yang, G., Choi, M., and Lee, J.

S., (1999), "An Experimental Study of Slot Jet Impingement Cooling on Concave Surface: Effects of Nozzle Configuration and Curvature", Int. J. Heat Mass Transfer, vol. 42, no. 12, pp. 2199-2209.

25- Zhang, H., Huang, Y., Sun, Z., (2006), "A study of mass flow rate measurement based on the vortex shedding principle", Flow Measurement and Instrumentation 17 (1) pp 29-38.

\section{NOMENCLATURE:}

$C_{h d} \quad$ power-height parameter

$D_{o} \quad$ Plenum chamber diameter

$D_{c} \quad$ Platform diameter

$h_{o} \quad$ Height of plenum chamber

$V_{j} \quad$ Jet exit velocity $\mathrm{m} / \mathrm{s}$

$L \quad$ jet height

$L_{j} \quad$ nozzle-plate spacing

$L_{j} / D_{c} \quad$ Non dimensional gap

$\dot{m}_{j} \quad$ Mass flow rate

p Time averaged gauge pressure

$\bar{P} \quad$ Time space averaged pressure

$\dot{Q}_{j} \quad$ Jet volume flow rats

$\mathrm{R} \quad$ Cushion to total gauge pressure ratio $R=P_{c} / P_{o}$

$t_{j} / D_{c} \quad$ Jet thickness Ratio

$\alpha \quad$ Conical angle of the nozzle

$\theta_{\mathrm{j}} \quad$ Conical jet angle

\section{Subscripts}

a atmosphere

c cushion

j jet

o Plenum chamber 